\title{
Impact of pre-oxidation treatments on performances of pitch-based hard carbons for sodium-ion batteries
}

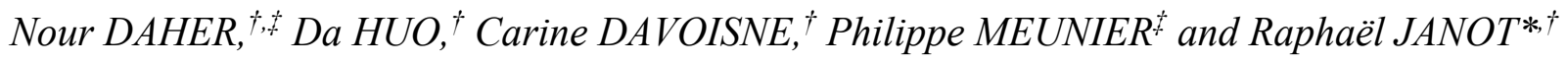 \\ † Laboratoire de Réactivité et Chimie des Solides (LRCS), UMR 7314 CNRS Université de \\ Picardie Jules Verne, 33 rue St-Leu, 80039 Amiens, FRANCE. \\ $\$$ MERSEN France Gennevilliers, 41 rue Jean Jaurès 92231 Gennevilliers Cedex, FRANCE.
}

KEYWORDS. Energy storage, Na-ion battery, hard carbon, pitch, Raman spectroscopy, XPS, porosity.

ABSTRACT. Recently, sodium-ion batteries have been intensively studied as an alternative to lithium-ion batteries because of the abundance of sodium and its ability, for example, to answer to smart grid energy storage applications. Among all anode materials, carbonaceous materials have shown promising results, particularly hard carbons owing to their high capacity and low insertion voltage $\left(v s . \mathrm{Na}^{+} / \mathrm{Na}\right)$. However, these materials often suffer from their high cost and low initial coulombic efficiency. In this paper, we investigate an easy route of hard carbon synthesis from low-cost pitch precursor. A pre-treatment under a controlled atmosphere can hinder the graphitization of the pitch upon pyrolysis and induce an amorphous-like microstructure with high 
Na storage capacity. We also investigate the mechanism of pre-oxidation and show the importance of parameters optimization such as the atmosphere and the duration. This work highlights the influence of the pre-treatment conditions on the hard carbon characteristics which are of key importance to explain and improve its electrochemical performances. The control of the preoxidation conditions allowed us to obtain a unique hard carbon with optimized micro-structure and texture and delivering impressive electrochemical performances. This hard carbon was obtained from a 12 -hour pre-treatment at $300^{\circ} \mathrm{C}$ under oxygen flow followed up by a 2-hour carbonization at $1400^{\circ} \mathrm{C}$ under nitrogen with a high yield of $49 \%$. This material delivers remarkable $312 \mathrm{mAh} . \mathrm{g}^{-}$ ${ }^{1}$ of reversible capacity at $\mathrm{C} / 20$ for only $10 \%$ of irreversibility at the first cycle, which correspond to the best electrochemical performances reported so far for pitch-based hard carbons. This work definitively emphasizes the potential of pitch-based hard carbons for further industrialization of sodium-ion batteries.

\section{INTRODUCTION}

Environmental issues are nowadays more and more pushing towards the development of renewable energies. ${ }^{1}$ These alternative choices are facing the problem of energy storage. ${ }^{2}$ So far, lithium-ion batteries (LIBs) have been largely used and efficient in most portable electronic devices. However, for stationary large-scale energy storage, most used electrochemical systems today are the traditional lead-acid batteries and the sodium-sulfur batteries. The former requires large installations, contains toxic heavy metals and suffers from severe self-discharge while the latter raises other safety and operational issues because of its high operating temperature: 300 to

$350^{\circ} \mathrm{C}^{3}$ Unfortunately, room-temperature LIBs cannot address the problem of large-scale energy 
storage, mainly because lithium has a relatively low abundancy in the earth's crust and its uneven global distribution makes it more and more expensive. ${ }^{4-6}$

Sodium is the second alkali metal below lithium in the periodic table and has similar physico-chemical properties. It has been studied to replace lithium because of its abundancy in the earth's crust (sodium is the $6^{\text {th }}$ most abundant element) and because it can be easily extracted which makes it a cheap resource. ${ }^{6-8}$ In addition, unlike lithium, sodium does not form alloys with aluminum thus sodium-ion batteries (SIBs) do not require the use of copper foil as a current collector for the negative electrode, less expensive aluminum foil is suitable. ${ }^{9,10}$ Positive electrodes and electrolytes have already been extensively studied and optimized to obtain SIBs with the best possible performances. ${ }^{10}$ Nevertheless, graphite used as the negative electrode for LIBs shows very low electrochemical performances as an anode for SIBs because of the weaker binding energy of sodium to graphite, it only forms high stage graphite-intercalation compounds with sodium (stage $8=\mathrm{NaC}_{64}$ ). ${ }^{8}{ }^{11}$ Many other materials have been investigated as negative electrode of sodium-ion batteries such as alloys based on tin or antimony, ${ }^{12-14}$ metal oxides ${ }^{15-19}$ or organic compounds, ${ }^{20-23}$ which have however poor cycling behavior and/or poor structural stability despite their high capacities. Among all the compounds tested as negative electrodes, carbonaceous materials and mainly non-graphitizable carbons (called hard carbons) showed the best hopes for SIBs. Thanks to their amorphous structure and their large interlayer spacing, sodium can insert in a much larger quantity, although the exact mechanism of sodium storage still arises some questions. ${ }^{24-27}$ However, the main reported issues of these carbons are a low initial coulombic efficiency (ICE) (very often not exceeding $80 \%)^{28-30}$ and a poor cycling behavior at high current densities. 
A large variety of materials has been reported as precursors for hard carbons synthesis and further used as negative electrode of SIBs such as sucrose, ${ }^{28,31-33}$ cellulose,${ }^{34-36}$ phenolic resins, ${ }^{37-42}$ lignins, ${ }^{43,44}$ and other types of biomass. ${ }^{45-49}$ Although they are abundant, sucrose and cellulose suffer from high cost and very low carbon yields $(<20 \%)$. Phenolic resins instead have better carbon yields but their toxicity and price can hinder their use for large application of SIBs. Biomass is green-resource and has a positive waste management impact but its wide diversity and high dependence on season and geographic location induce a low reproducibility that limits their interest as hard carbon precursors. ${ }^{41}$

Petroleum pitch is a very interesting carbon precursor because of its high carbon yield $(>50 \%)$ and its low cost. However, this petrochemical byproduct is more known as a precursor of soft carbons and synthetic graphite and is not a usual precursor of carbon-based anode materials for SIBs due to its graphitization upon heating. Only in 2011, the first pitch-based anode material for SIBs was reported by Wenzel et al. delivering a storage capacity of about $130 \mathrm{mAh} \cdot \mathrm{g}^{-1}$ with only $14 \%$ of coulombic efficiency at the first cycle. ${ }^{50}$ This work gave rise to more recent reports where authors tried different methods to restrain pitch graphitization. Li et al. first tried to mix pitch with phenolic resin and were able to obtain a hard carbon delivering $284 \mathrm{mAh} \cdot \mathrm{g}^{-1}$ as reversible capacity for an initial coulombic efficiency of $88 \%{ }^{51}$ Later on, the same group did the same work but replace phenolic resin by lignin which is less expensive and comes from biomass resources. Their best sample reached a first reversible capacity of $254 \mathrm{mAh} \cdot \mathrm{g}^{-1}$ with an ICE of $82 \% .{ }^{52}$ Yang et al. reported a composite made of reduced graphite oxide and pitch with an initial discharge capacity of $268 \mathrm{mAh} \cdot \mathrm{g}^{-1}$ for $79 \%$ of coulombic efficiency at the first cycle (under a 20 mA.g ${ }^{-1}$ current density) ${ }^{53}$ Pitch was used here to reduce the expansion of graphite oxide during its reduction and to fill its porosity in order to decrease the specific surface area. More recently, 
Lu et al. explored another way to reduce pitch graphitization and suggested to pre-oxidize the precursor in order to introduce cross-linking between the Basic Structural Units (BSUs) within the structure. They successfully used this carbon material as negative electrode for SIBs reaching for the first time, with a pitch-based material, $300 \mathrm{mAh} \cdot \mathrm{g}^{-1}$ as first reversible capacity and $88 \%$ of initial coulombic efficiency. ${ }^{54}$ This work is of great interest because it finally demonstrates that high electrochemical performances can be obtained with pitch-based hard carbons.

Based on the energy cost for the precursors production (as found in the ecoinvent database) and the expertise of our industrial partner, it was estimated that the process for the pitch-derived hard carbon synthesis developed here could lead to an energy cost improvement of about $20 \%$ compared to a typical phenolic resin-derived hard carbon process. Our aim was, therefore, to further study the use of petroleum pitch as carbon precursor, to improve the pitch pre-oxidation treatment and to better understand this process on the microstructure of the resulting hard carbon material. The pre-oxidation atmosphere was studied as a key parameter to improve this step. All samples were analyzed by several characterization techniques and tested in half-cells as negative electrode for SIBs.

\section{EXPERIMENTAL SECTION}

\section{MATERIAL SYNTHESIS.}

Hard carbons were obtained by a two-step pyrolysis reaction of commercially available petroleum pitch. The as-received raw granules were first crushed into smaller particles in an agate mortar and then pre-oxidized at $300^{\circ} \mathrm{C}$ for different durations $(3,12,48,72$ and 200 hours) 
and under different atmospheres (ambient air, oxygen flow, air flow) in order to investigate the effect of the pre-oxidation step. The oxygen flow (Oxygen, Air Liquide Alphagaz ${ }^{\mathrm{TM}} 1,99.995 \%$ ) and the air flow were $20 \mathrm{cc} \cdot \mathrm{min}^{-1}$. Then, the obtained pre-oxidized materials were carbonized for $2 \mathrm{~h}$ in a tubular furnace under nitrogen flow $\left(200 \mathrm{cc} \cdot \mathrm{min}^{-1}\right)\left(\right.$ Nitrogen, Air Liquide Alphagaz ${ }^{\mathrm{TM}} 1$, $99.999 \%$ ) at $1400^{\circ} \mathrm{C}$. The hard carbons derived from pre-oxidized pitches were referred to as HCPOP-atm $X$ where atm refers to the atmosphere of pre-oxidation (air, oxygen) and $X$ the duration of the pretreatment (in hours). For comparison, the pristine pitch was directly carbonized at $1400^{\circ} \mathrm{C}$ and noted as $\mathrm{HCP}$.

\section{CHARACTERIZATIONS.}

Thermo-gravimetric analysis (TGA) was performed to study the mass loss of the petroleum pitch during the pre-oxidation step at temperatures up to $300^{\circ} \mathrm{C}$ at $5^{\circ} \mathrm{C} \cdot \mathrm{min}^{-1}$ under air (Netzsch STA449C Jupiter equipped with a mass spectrometer).

The structure of the hard carbons was studied by Raman spectroscopy and powder X-ray diffraction (XRD). Raman measurements were performed at room temperature using a ThermoScientific microscope DXR spectrometer equipped with He-Ne excitation source (532 nm wavelength) and Olympus microscope. XRD analysis was performed using a Bruker AXS D8 Advance diffractometer equipped with a $\mathrm{CuK}_{\alpha}$ radiation source $(\lambda=1.5418 \AA)$.

The microstructural investigation was performed using a FEI Tecnai F20-S-TWIN operating at $200 \mathrm{kV}$ through High Resolution Transmission Electron Microscopy (HRTEM) and 
associated Fast Fourier Transform (FFT). The samples were dispersed in ethanol and two drops were deposited on a copper grid with holey carbon.

Textural properties of the hard carbon materials were investigated with a Micromeritics ASAP 2020 analyzer using $\mathrm{N}_{2}$ gas as adsorbate $(77 \mathrm{~K})$. The samples were first degassed at $150^{\circ} \mathrm{C}$ for $1 \mathrm{~h}$ and then $300^{\circ} \mathrm{C}$ for $12 \mathrm{~h}$, under primary vacuum. The BET (Brunauer-EmmettTeller) specific surface area $\mathrm{S}_{\mathrm{BET}}$ was determined from the linear plot in the relative pressure range $0.05-0.3\left(\mathrm{P} / \mathrm{P}_{0}\right)$.

X-ray photoelectron spectroscopy (XPS) experiments were carried out in a Kratos AXIS Ultra DLD spectrometer, using a monochromatic $\mathrm{Al} \mathrm{K} \alpha \mathrm{X}$-ray source $(1486.6 \mathrm{eV})$ with a power of $225 \mathrm{~W}(15 \mathrm{~mA}, 15 \mathrm{kV})$. Instrument base pressure inside the analysis chamber was $5.0 \times 10^{-9}$ Torr. The C 1s and $\mathrm{O}$ 1s high-resolution spectra were collected using an analysis area of about $300 \mu \mathrm{m} \times 700 \mu \mathrm{m}$ and a $20 \mathrm{eV}$ pass energy. The bending energy scale was calibrated taking $\mathrm{C} 1 \mathrm{~s}$ peak at $284.8 \mathrm{eV}$ as a reference. All spectra were peak-fitted using CasaXPS software (version 2.3.16, Casa Software Ltd.).

Elemental analyses were performed using a Thermofisher Flash EA 1112 apparatus, and contents of $\mathrm{C}, \mathrm{H}, \mathrm{N}, \mathrm{S}$ and $\mathrm{O}$ were measured. Results were all registered and analyzed using Eager 300 software. At least two runs of measurements were performed for each sample and the accuracy is $\pm 0.3 \%$.

\section{CELL ASSEMBLY AND ELECTROCHEMISTRY.}


Electrochemical investigations were conducted in CR2032-type coin cells of $20 \mathrm{~mm}$ diameter with sodium metal as the counter electrode. Whatman ${ }^{\circledR}$ glass fiber was used as the separator impregnated with $150 \mu \mathrm{L}$ of NP30 electrolyte i.e. a solution of $1 \mathrm{M} \mathrm{NaPF}_{6}$ in ethylene carbonate (EC; Merck 99.9\%) and dimethyl carbonate (DMC; Sigma-Aldrich, anhydrous $\geq 99 \%$ ) (1:1 in weight). The water content of the prepared electrolyte was measured by coulometric KarlFischer titration and found to be lower than $15 \mathrm{ppm}$. All the operations were performed in an Argon-filled glove box $\left(\mathrm{H}_{2} \mathrm{O}, \mathrm{O}_{2}<0.1 \mathrm{ppm}\right)$. Galvanostatic tests were carried out on a BioLogic SAS BCS-805 battery test system at room temperature $\left(T=24.4 \pm 0.5^{\circ} \mathrm{C}\right)$ within a potential window ranging from 0 to $2.5 \mathrm{~V} v s$. Na ${ }^{+} / \mathrm{Na}$. The cycling was performed down to $0 \mathrm{~V}$ as it was previously checked that no Na plating occurs at the rate of $\mathrm{C} / 10$ for our prepared hard carbons: the Na plating typically occurs around $-30 \mathrm{mV} v s . \mathrm{Na}^{+} / \mathrm{Na}$ under this condition and using NP30 electrolyte. The theoretical specific capacity of the carbon sample was taken at $372 \mathrm{mAh} \cdot \mathrm{g}_{\text {carbon }}{ }^{-1}$ corresponding to the hypothetical $\mathrm{NaC}_{6}$ formation (therefore a current rate of $1 \mathrm{C}$ corresponds to $\left.372 \mathrm{~mA} \cdot \mathrm{g}_{\text {carbon }}{ }^{-1}\right)$. Constant current charge/discharge rate of C/20 was applied for 10 cycles followed by 100 cycles at C/10. Two cells were evaluated for each sample to ensure reproducibility of the results. The electrochemical capacities given in the article are the average values obtained from these two different electrochemical cells.

\section{RESULTS AND DISCUSSION}

\section{HARD CARBON CHARACTERIZATIONS.}

A sample of pristine pitch was first carbonized at $1000^{\circ} \mathrm{C}$ and shows the remarkable difference of structural order when compared to a commercial $\mathrm{HC}$ and a common sucrose- 
derived HC (Figure S1, Supporting Information). These XRD diagrams are characterized by two broad peaks observed at $22-24^{\circ}$ and $43-45^{\circ}$ corresponding respectively to (002) and the (101) family of diffraction planes of graphene sheets stacking. The HCs exhibiting the best $\mathrm{Na}$ electrochemical insertion performances usually display broad peaks suggesting low graphitization degree, as shown on sucrose-derived HC and commercial one in Figure S1. Their interlayer spacing $\mathrm{d}_{002}$ are of $3.9 \AA$ and $3.7 \AA$ respectively, proof of their low graphitization degree. However, pitch-derived HC is clearly not amorphous enough as the (002) peak is much narrower and the interlayer spacing $\mathrm{d}_{002}$ is relatively small with a value of the order of $3.5 \AA$. As a comparison, graphite exhibits an interlayer spacing of $3.35 \AA$.

A soft pretreatment was performed on pitch by pre-oxidizing it at $300^{\circ} \mathrm{C}$ in a muffle furnace under air during 3 hours. The HC derived from this material (overall yield of 65\%) was still too graphitized as shown in Figure 1a. Indeed, HCPOP-air3 exhibits a well-defined (002) peak. A harsher pre-oxidation treatment was then conducted on pitch by annealing at $300^{\circ} \mathrm{C}$ in a tubular furnace for 12 hours under oxygen flow. After pyrolysis, the overall yield is $49 \%$ which is still high for HC synthesis. XRD diagrams of all three samples, pristine pitch, air pre-oxidized pitch, and oxygen pre-oxidized pitch, -derived HCs are presented in Figure 1a and show the strong impact of pre-oxidation under oxygen flow on the structural order. Indeed, HCP (002) peak is well defined whereas HCPOP-ox12 (002) peak is much broader and closer to what is expected from a promising hard carbon for $\mathrm{Na}$ insertion. HCPOP-air3 shows an in-between crystallinity state. Average crystallite sizes $\mathrm{L}_{\mathrm{c}}$ (thickness of the graphitic domains) and $\mathrm{L}_{\mathrm{a}}$ (length of the graphitic domains) were calculated using Scherrer equation (1) on the (002) and (101) reflections respectively: 


$$
L=\frac{\mathrm{k} \cdot \lambda}{\mathrm{FWHM} \cdot \cos \theta}
$$

where $\mathrm{k}$ is a corrective factor considering the shape of the peaks. This $\mathrm{k}$ factor is valued at 1.84 for $\mathrm{L}_{\mathrm{a}}$ and 0.89 for $\mathrm{L}_{\mathrm{c}}$ as described in P. Mallet's PhD thesis. ${ }^{55}$ The (002) peak is fitted with a Lorentzian peak and the (101) one with 2 Pearson VII peaks. ${ }^{55}$ Crystallite sizes and interlayer spacing between graphene sheets, obtained from the (002) peak position, are reported in

Table 1. The interlayer spacing $\mathrm{d}_{002}$ increases from $3.5 \AA$ for HCP and for HCPOP-air3, to about $3.7 \AA$ for $\mathrm{HCPOP}-\mathrm{ox} 12$, while $\mathrm{L}_{\mathrm{c}}$ and $\mathrm{L}_{\mathrm{a}}$ decrease showing that the structure loses progressively its order. The graphitic domains, called basic structural units (BSUs), are the smallest when pitch is pre-oxidized under oxygen for 12 hours. The $\mathrm{L}_{\mathrm{c}}$ crystallite size for this latter $\mathrm{HC}$ is especially very small, only $11.5 \AA$, thus corresponding to the stacking of only 4 graphene sheets whereas HCP displays up to 11 graphene sheets. This treatment under oxygen flow leads therefore to a strong modification of the pitch-derived hard carbons structure.
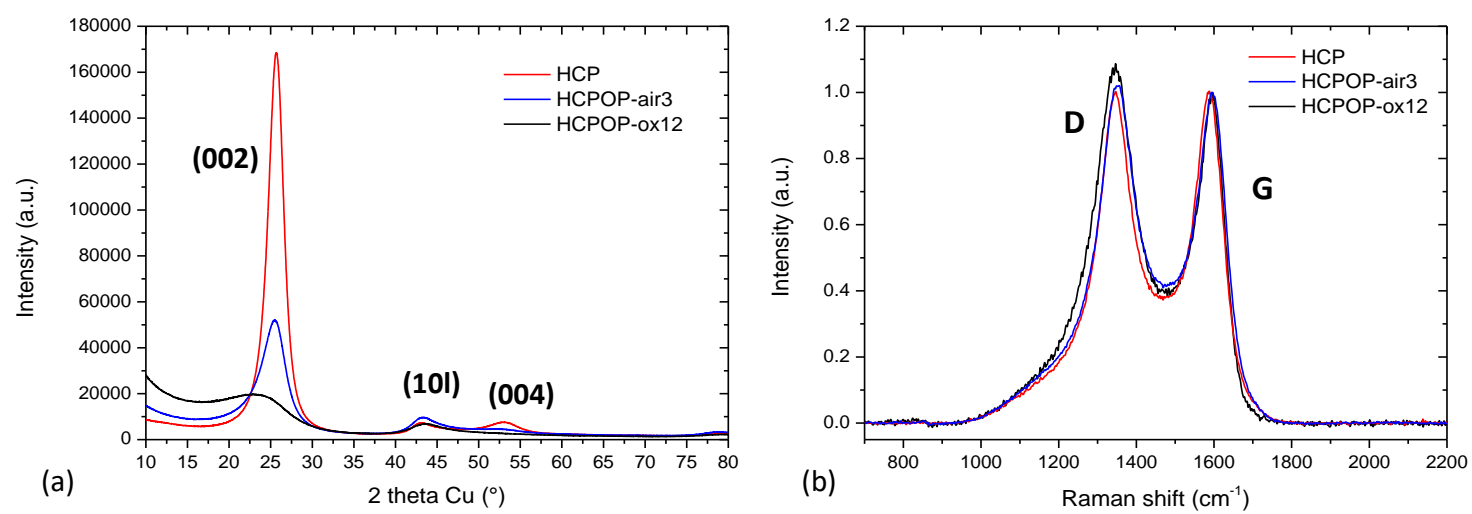

Figure 1. (a) XRD diagrams and (b) Raman spectra of HCP, HCPOP-air3 and HCPOP-ox12. 
Additional characterization tests were conducted on these three samples in order to understand better the structural evolution. Raman spectroscopy was performed and the spectra display two intense bands in the $1100-1700 \mathrm{~cm}^{-1}$ range (cf. Figure 1b). The first band at around $1350 \mathrm{~cm}^{-1}$ corresponds to the defect-induced D-band due to a double resonance process. The second band at around $1590 \mathrm{~cm}^{-1}$ corresponds to the crystalline graphite G-band attributed to inplane vibrational mode of $\mathrm{sp}^{2}$-hybridized carbon. The ratio between the areas of fitted D and $\mathrm{G}$ bands $\left(\mathrm{A}_{\mathrm{D}} / \mathrm{A}_{\mathrm{G}}\right)$ can inform on the graphitization degree of the material. Many different models of band fits and area calculations exist in literature ${ }^{56-60}$ but the one used here is developed by Monthioux's team ${ }^{60}$ fitting the D-band with 2 Lorentzians sharing the same center and the Gband with a Breit-Wigner-Fano (BWF) equation taking into consideration its asymmetrical feature. $A_{D} / A_{G}$ values are reported in

Table 1. Variation of the $A_{D} / A_{G}$ ratio once again shows the amorphization of the $\mathrm{HC}$ structure occurring after pre-oxidation of the carbon precursor. HCPOP-ox12 exhibits the highest $\mathrm{A}_{\mathrm{D}} / \mathrm{A}_{\mathrm{G}}$ ratio of 1.9 which indicates the highest degree of structural disorder. This emphasizes the structural impact of the pre-oxidation step under oxygen.

Table 1. Structural characteristics of the HCs from XRD and Raman analyses.

\begin{tabular}{|l|l|l|l|l|}
\hline Sample & $\mathbf{d}_{\mathbf{0 0 2}}(\AA)$ & $\mathbf{L}_{\mathbf{c}}(\AA)$ & $\mathbf{L}_{\mathbf{a}}(\AA)$ & $\mathbf{A D}_{\mathbf{D}} / \mathbf{A}_{\mathbf{G}}$ \\
\hline HCP & 3.5 & 36.0 & - & 1.5 \\
\hline HCPOP-air3 & 3.5 & 23.5 & 51.9 & 1.7 \\
\hline HCPOP-ox 12 & 3.7 & 11.5 & 43.3 & 1.9 \\
\hline HCPOP-air12 & 3.5 & 14.5 & 45.0 & 1.91 \\
\hline
\end{tabular}




\begin{tabular}{|l|l|l|l|l|}
\hline HCPOP-air48 & 3.6 & 12.6 & 43.9 & 1.94 \\
\hline HCPOP-air72 & 3.6 & 12.1 & 43.2 & 1.98 \\
\hline HCPOP-air200 & 3.6 & 11.7 & 43.4 & 1.95 \\
\hline
\end{tabular}

A TEM study has been done to investigate the microstructure of these samples (HCP, HCPOP-air3, HCPOP-ox12). For HCP (cf. Figure 2a and b), organized and stacked layers of graphene are observed in very large areas. On the one hand, typical graphitized microstructure can be seen with very long and thick parallel graphene layers all in one direction such as in Figure 2b. On the other hand, some randomly oriented stacks also exist but remain of great amount and size (cf. Figure 2a). The FFTs associated to both areas exhibit two relatively well defined rings. In Figure 2b, the first ring attributed to (002) diffraction plane is actually an arc highlighting the preferred orientation of the graphene layers. In both areas, the average interlayer spacing measured in the HRTEM and in the FFT mode is $3.5 \AA$ which is in good agreement with the X-ray characterization. HCPOP-air3 presents a more disorganized microstructure with smaller BSUs, randomly oriented as in Figure 2c, and with an average interlayer spacing of 3.6 A based on HRTEM and FFT measurements. The FFT rings are a little more diffuse showing a slightly less organized structure. However, some graphite-like areas with very long and thick parallel graphene layers all in one direction can also be found (cf. Figure 2d) but in a lesser amount. This is once again represented in the FFT by an arc. The average interlayer spacing measured both by HRTEM and FFT is $3.5 \AA$. These two domains explain the shape of HCPOPair3 XRD diagram where the (002) peak is broader than in HCP. In the case of HCPOP-ox12, the TEM observation exhibits two different microstructures. The first one is highly disorganized and no BSUs are observed which gives an amorphous signal through the FFT mode (cf. Figure 2e). 
The second microstructure is composed of spherical particles of around $150 \mathrm{~nm}$ diameter in which the graphene layers follow the rounded shape of the grain. The FFT performed on these areas presents an even more diffusive contribution than with the first samples indicating a variation of the parameter along the $\mathrm{c}$ axis. Moreover, the (002) ring is smaller showing a larger interlayer spacing of 3,7 $\AA$ (cf. Figure 2f). These two types of arrangement (amorphous phases and rounded shape particles) explain the very broad (002) peak in the XRD characterization. These observations show that the pre-oxidation can indeed hinder the graphitization of the pitch. 


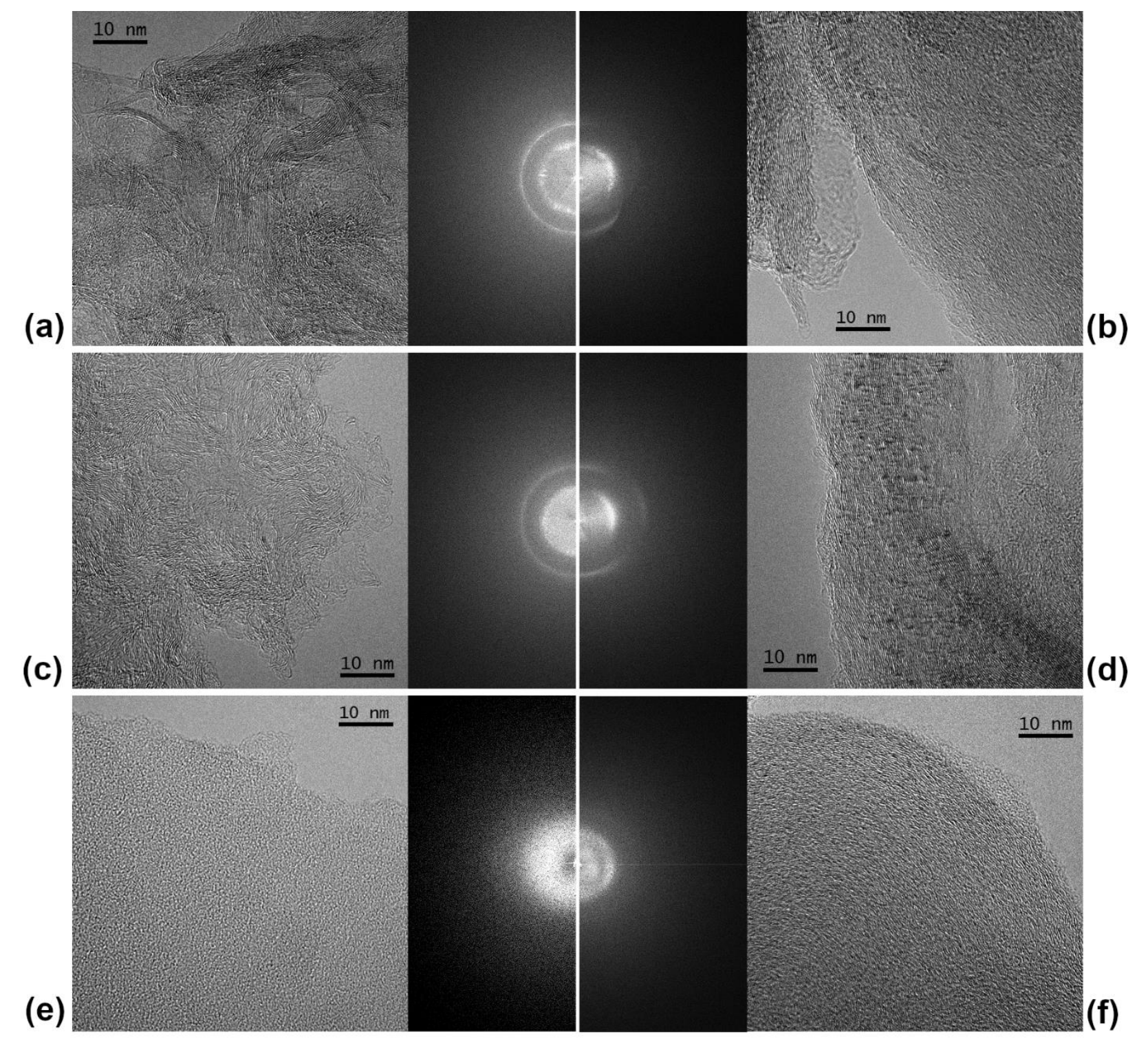

Figure 2. HRTEM micrographs and associated FFT of (a-b) pristine-pitch-derived HC, (c-d) 3hour-air pre-oxidation pitch-derived HC and (e-f) 12-hour-oxygen pre-oxidation pitch-derived $\mathrm{HC}$.

The pre-oxidation under oxygen flow is really efficient and offers very promising results but using pure oxygen flow makes it harder to consider industrializing such a process. For that 
reason, the same pretreatment was redone using air flow instead. A series of samples was prepared in order to highlight the impact of the pre-oxidation time, ranging from 12 hours to 200 hours. The XRD diagrams are depicted in Figure S2 (Supporting Information). The amorphization of the structure really improves when pre-oxidation time increases as revealed by the broadening of (002) peak. Decreasing $\mathrm{L}_{\mathrm{c}}$ crystallite size also proves the same point. However, it also highlights the limit reached by this optimization. Indeed, from 12 hours to 48 hours, $\mathrm{L}_{\mathrm{c}}$ decreases by $13 \%$ from $1.45 \mathrm{~nm}$ to $1.26 \mathrm{~nm}$, but from 48 hours to 200 hours it only decreases by $7 \%$ from $1.26 \mathrm{~nm}$ to $1.17 \mathrm{~nm}$. The same observation can be made with $\mathrm{L}_{\mathrm{a}}$ crystallite size in a smaller extent. Raman spectroscopy was also done on these samples and the $A_{D} / A_{G}$ values are reported in

Table 1. Evolution is very low but an increase in this ratio is noticeable from 1.91 to 1.98 for 12-hour and 72-hour respectively, showing a slight amorphization of the structure. $A_{D} / A_{G}$ then decreases to 1.95 after a pre-oxidation of 200 hours.

Thermal analysis (TGA) was employed to investigate the pre-oxidation step of pitch by studying the mass gain and the gases removal when the precursor is annealed to $300^{\circ} \mathrm{C}$ at $5^{\circ} \mathrm{C} . \mathrm{min}^{-1}$ for 12 hours under air. TGA curve (cf. Figure S3, Supporting Information) shows that the sample weight uptake during the first two hours is $4.5 \%$ which is related to the oxygen inclusion into the material and only then the mass loss occurs very slowly due to the pitch decomposition. The gases detected by the mass spectrometer are water and carbon dioxide. This shows the importance of the kinetics of the pretreatment and the need to find an optimum preoxidation duration that allows efficient oxygen incorporation into the pitch before molecules volatilization occurs degrading the material. Indeed, carbon yield decreases from $64 \%$ for the 12 - 
hour pre-oxidized pitch-derived $\mathrm{HC}$ to $33 \%$ for the 200 -hour one. That may explain also why a limit in structure amorphization is reached after 48-72 hours of air pre-oxidation.

Elemental analyses were conducted on five samples before and after pyrolysis at $1400^{\circ} \mathrm{C}$ and the data are depicted in

Table 2. Before pyrolysis, the results show that carbon content is decreasing with increasing pre-oxidation time while oxygen content clearly increases (Figure 3a). From 3-hour ambient air pre-oxidation to 200 -hour air flow pre-oxidation, $\mathrm{C}$ content decreases from 89.4 to $63.8 \mathrm{wt} \%$ and $\mathrm{O}$ content increases from 2.1 to $32.2 \mathrm{wt} \%$. Increasing oxygen content would help creating reticulations in the structure which is in good agreement with hindering the graphitization process during pyrolysis. Hydrogen content decreases but with a less obvious evolution. After pyrolysis, all oxygen content disappeared letting a material containing almost only carbon as reported in

Table 2 .

Table 2. Carbon, hydrogen and oxygen contents from elemental analyses for different treated, or not treated, pitch samples before and after pyrolysis.

\begin{tabular}{|c|c|c|c|c|c|c|c|}
\hline \multicolumn{4}{|c|}{ Before pyrolysis } & \multicolumn{4}{c|}{ After pyrolysis at 1400 ${ }^{\circ} \mathbf{C}$} \\
\hline Sample & $\begin{array}{c}\text { C content } \\
(\mathbf{w t} \%)\end{array}$ & $\begin{array}{c}\text { H content } \\
(\mathbf{w t} \%)\end{array}$ & $\begin{array}{c}\text { O content } \\
(\mathbf{w t} \%)\end{array}$ & Sample & $\begin{array}{c}\text { C content } \\
(\mathbf{w t} \%)\end{array}$ & $\begin{array}{c}\text { H content } \\
(\mathbf{w t} \%)\end{array}$ & $\begin{array}{c}\text { O content } \\
(\mathbf{w t} \%)\end{array}$ \\
\hline P-N2 & 94.2 & 5.5 & $<0.05$ & HCP & 94.9 & 0.1 & $<0.05$ \\
\hline POP-air3 & 89.4 & 4.8 & 2.1 & $\begin{array}{c}\text { HCPOP- } \\
\text { air3 }\end{array}$ & 99 & $<0.05$ & $<0.05$ \\
\hline POP-ox12 & 78.8 & 2.9 & 14.3 & $\begin{array}{c}\text { HCPOP- } \\
\text { ox12 }\end{array}$ & 99 & 0.2 & $<0.05$ \\
\hline
\end{tabular}




\begin{tabular}{|c|c|c|c|c|c|c|c|}
\hline POP-air48 & 71.4 & 2.4 & 22.7 & $\begin{array}{c}\text { HCPOP- } \\
\text { air48 }\end{array}$ & 96.3 & 0.3 & $<0.05$ \\
\hline $\begin{array}{c}\text { POP- } \\
\text { air200 }\end{array}$ & 63.8 & 1.9 & 32.2 & $\begin{array}{c}\text { HCPOP- } \\
\text { air200 }\end{array}$ & 93.7 & 0.3 & $<0.05$ \\
\hline
\end{tabular}

XPS analyses were conducted on these same five samples after pyrolysis. The first survey of spectra highlights only two peaks at $284.6 \mathrm{eV}$ and $533.2 \mathrm{eV}$ attributed to $\mathrm{C} 1 \mathrm{~s}$ and $\mathrm{O} 1 \mathrm{~s}$, respectively. As elemental results already showed, there is no huge difference between the samples after pyrolysis (Table S1, Supporting Information) but it allowed to confirm the presence of $\mathrm{C}-\mathrm{O}$ bonding at the surface of the carbons. High-resolution spectra of $\mathrm{O} 1 \mathrm{~s}$ were all similar whereas that of $\mathrm{C} 1 \mathrm{~s}$ revealed a slight increase of $\mathrm{C}-\mathrm{O}$ bonding contribution (Figure S4, Supporting Information) from the pristine-pitch-derived hard carbon HCP to the oxygen preoxidized pitch-derived hard carbon HCPOP-ox 12, showing the impact of the pretreatment under oxygen flow. The areas of the fitted peaks are depicted in Figure 3b showing the evolution of C $-\mathrm{O}$ bonds at the surface of the samples. $\mathrm{C}-\mathrm{OH}$ and $\mathrm{C}-\mathrm{O}-\mathrm{C}$ bond-type contributions increase from $5.2 \%$ to $13.7 \%$ from the 3 -hour ambient air pre-oxidation $\mathrm{HC}$ to the 200 -hour air flow preoxidized $\mathrm{HC}$ whereas $\mathrm{C}=\mathrm{O}$ bond-type contribution seems to decrease slightly. The latter observation is attributed to the $\mathrm{CO}_{2}$ release upon prolonged heat treatment. XPS analyses on treated pitches before pyrolysis were unfortunately not possible due to contamination of the analysis chamber by aromatic molecules. 

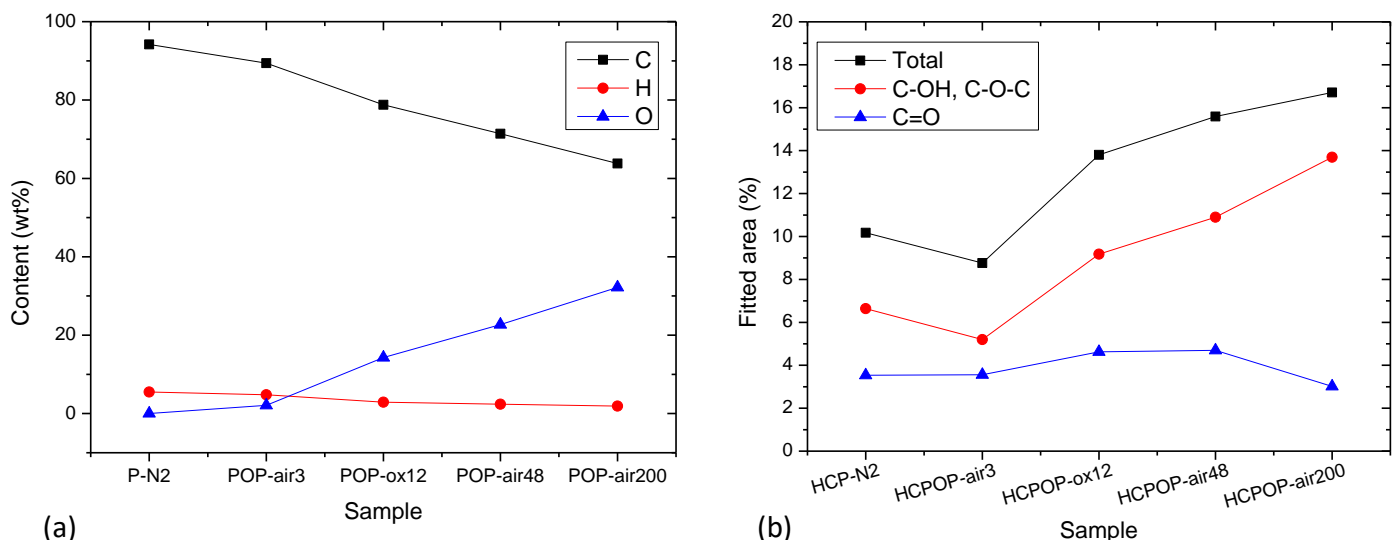

Figure 3. (a) Carbon, hydrogen and oxygen contents from elemental analyses for different treated, or not treated, pitch samples before pyrolysis. (b) Fitted area of C - O bonds based on high resolution $\mathrm{C} 1 \mathrm{~s}$ spectra at the surface of different treated, or not treated, pitch-derived hard carbons.

Presence of defects in hard carbon structure is of great diversity. It ranges from $\mathrm{sp}^{3}$ hybridized carbons to mono- or di- vacancies, dangling bonds, and extreme curvature in graphene sheets. ${ }^{26} \mathrm{~A}$ dangling bond implies the presence of an under-coordinated carbon atom which makes it a defect of high formation energy. ${ }^{61}$ The pyrolysis allows these defects to form as the atoms are not in the thermodynamic equilibrium during the process. ${ }^{62}$ The formation of dangling bonds often comes along with strains in the system due to the removal of a carbon atom. These features cause an increase of the reactivity of the carbon atoms in the vicinity of the vacancy where sodium can very strongly attach. ${ }^{63}$ This is partly the cause of a high irreversibility at first cycle in sodium-ion batteries. ${ }^{49,63,64}$ Dangling bonds are also likely inclined to lead to binding with other graphene sheets and therefore to reticulate the structure. ${ }^{63}$ We hypothesize that this phenomenon is presumably occurring with the help of the pre-oxidation process which already reticulates the structure by incorporation of oxygen. Dangling bonds density in preoxidized derived hard carbons, such as HCPOP-ox12, is therefore greatly decreased which is consistent with the increase of the initial coulombic efficiency, as it will be discussed later. 
Similar to hydrogen addition in hard carbon structure by $\mathrm{H}_{2}$ reduction, the oxygen addition arising from the pre-oxidation is expected to occur with surface dangling bonds or other defect sites. Moreover, in the case of hydrogen incorporation, this occurrence has shown to immensely reduce the first irreversible loss in lithium-ion batteries. ${ }^{44}$

The porosities and the specific surface areas of the synthesized HCs were studied by nitrogen adsorption/ desorption analyses. All the samples show a mixture of Type I and II isotherms. The adsorption isotherms of HCP, HCPOP-air3 and HCPOP-ox12 are depicted in Figure 4. It is noticeable that the first point at very low relative pressure $\mathrm{P} / \mathrm{P}_{0}$ is high which is evidence of microporosity within the texture. The oxygen pre-oxidized pitch-derived hard carbon shows a higher adsorbed volume than the pristine pitch-derived hard carbon and the air preoxidized pitch-derived hard carbon. This indicates larger microporous volume in HCPOP-ox12, with $1.5 \mathrm{~cm}^{3} \cdot \mathrm{g}^{-1}$ quantity adsorbed which is more than three times higher than HCP's value with only $0.4 \mathrm{~cm}^{3} \cdot \mathrm{g}^{-1}$. However, further analyses such as $\mathrm{CO}_{2}$ adsorption would be necessary to fully describe the ultra-microporosity of these hard carbons. 


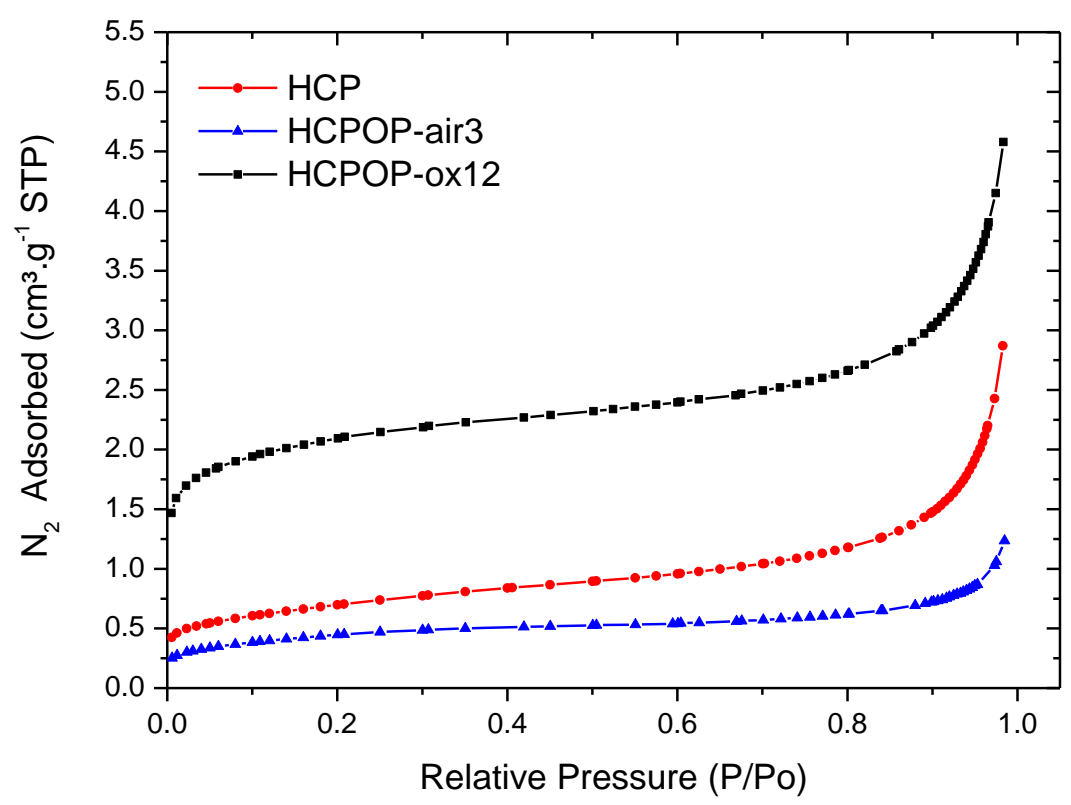

Figure 4. Nitrogen adsorption isotherms of HCP, HCP-air3 and HCP-ox12.

BET specific surface areas are calculated from these nitrogen adsorption isotherms and results are reported in

Table 3. HCP and HCPOP-air3 exhibit surprisingly low surface of $\mathrm{S}_{\mathrm{BET}}=2.4 \mathrm{~m}^{2} . \mathrm{g}^{-1}$ and $1.5 \mathrm{~m}^{2} \cdot \mathrm{g}^{-1}$, respectively, whereas HCPOP-ox12 has a BET surface area of $6.6 \mathrm{~m}^{2} \cdot \mathrm{g}^{-1}$. HCs with low surface area $\left(<10 \mathrm{~m}^{2} \cdot \mathrm{g}^{-1}\right)$ are more valuable as negative electrode of SIBs in order to reduce the irreversibility at first cycle. However, HCP and HCPOP-air3 do not have a suitable microstructure for sodium insertion because they are too graphitized as discussed previously. Nitrogen adsorption isotherms for all the other HCs derived from air-pre-oxidized pitches also present a mixture of Type I and II isotherms (cf. Figure S5, Supporting Information) and their S $\mathrm{BET}_{\mathrm{B}}$ increases with increasing pre-oxidation duration (cf. 
Table 3). Indeed, the HC sample derived from 12-hour-pre-oxidation under air exhibits $11 \mathrm{~m}^{2} \cdot \mathrm{g}^{-1}$ BET specific surface area and the one from 200-hour-pre-oxidation has a much higher $\mathrm{S}_{\text {BET }}\left(49.7 \mathrm{~m}^{2} \cdot \mathrm{g}^{-1}\right)$. Quantity of accessible micropores also increases as HCPOP-air12 exhibits 2.3 $\mathrm{cm}^{3} \cdot \mathrm{g}^{-1}$ of adsorbed $\mathrm{N}_{2}$ whereas this value reaches $12.2 \mathrm{~cm}^{3} \cdot \mathrm{g}^{-1}$ for HCPOP-air200.

Table 3. BET specific surface areas, densities and irreversibilities at first cycle of all the HCs studied.

\begin{tabular}{|c|c|c|c|}
\hline Sample & $S_{\text {BET }} \mathbf{N}_{2}\left(\mathbf{m}^{2} \cdot \mathrm{g}^{-1}\right)$ & $\begin{array}{c}\text { Irreversibility at } 1^{\text {st }} \\
\text { cycle }(\%)\end{array}$ & $d_{\text {pyeno }}\left(\mathrm{g} . \mathrm{cm}^{-3}\right)$ \\
\hline $\mathrm{HCP}$ & 2.4 & 37 & 2.08 \\
\hline HCPOP-air3 & 1.5 & 21 & 1.84 \\
\hline HCPOP-оx12 & 6.6 & 10 & 1.92 \\
\hline HCPOP-air12 & 11 & 14 & 1.88 \\
\hline HCPOP-air48 & 18.9 & 16 & 1.95 \\
\hline HCPOP-air72 & 7.2 & 13 & 1.95 \\
\hline HCPOP-air200 & 49.7 & 22 & 2.07 \\
\hline
\end{tabular}

Helium pycnometric densities have been measured for each sample and are reported in

Table 3. Values are all included between amorphous carbon $\left(1.5-1.8 \mathrm{~g} . \mathrm{cm}^{-3}\right)$ and graphite $\left(2.2 \mathrm{~g} . \mathrm{cm}^{-3}\right)$. The smallest density is obtained for HCPOP-air3 with $1.84 \mathrm{~g} . \mathrm{cm}^{-3}$ and the largest one is obtained for HCP with $2.08 \mathrm{~g} . \mathrm{cm}^{-3}$. The HC derived from a 12-hour pre-oxidized pitch under air flow has a density as low as HCPOP-air3 with $1.88 \mathrm{~g} . \mathrm{cm}^{-3}$ which indicates rather more non-accessible pores to $\mathrm{He}$ (closed pores, ultra-micropores) in the texture, whereas the $\mathrm{HC}$ derived from a 200-hour pre-oxidized pitch under air flow has a density just as high as HCP with $2.07 \mathrm{~g} . \mathrm{cm}^{-3}$ indicating lots of accessible pores in the texture. Pycnometric density increases with 
increasing pre-oxidation duration, which means that the samples tend to have less and less nonaccessible pores in their texture. HCPOP-air12 has a more porous structure than when the pitch is pre-oxidized for longer times (48, 72 and 200 hours).

All these results very precisely emphasize, for the first time, the impact of the preoxidation atmosphere and duration. We herein aim to call attention to the pre-treatment conditions in general as key parameters to tune the hard carbons structure.

\section{HARD CARBON ELECTROCHEMICAL PERFORMANCES.}

All the above characterized hard carbons were tested as negative electrodes of SIBs, in coin cells $v s$. sodium metal. First galvanostatic curves and cyclability behaviors were plotted for the non-treated pitch-derived hard carbon in comparison to the pre-oxidized ones (cf. Figure 5). The galvanostatic curves of a hard carbon electrode cycled against sodium are characterized by two regions: the slope region in the range of $0.1-2.5 \mathrm{~V} v s . \mathrm{Na}^{+} / \mathrm{Na}$ and the plateau region at low potential in the range of $0-0.1 \mathrm{~V} v s . \mathrm{Na}^{+} / \mathrm{Na}$. Although the mechanism of sodium insertion into $\mathrm{HC}$ structure is still discussed in literature, the plateau region is obviously of great interest to the electrode performance. The challenge is to have the longest plateau while maintaining the lowest irreversibility at the first cycle. 

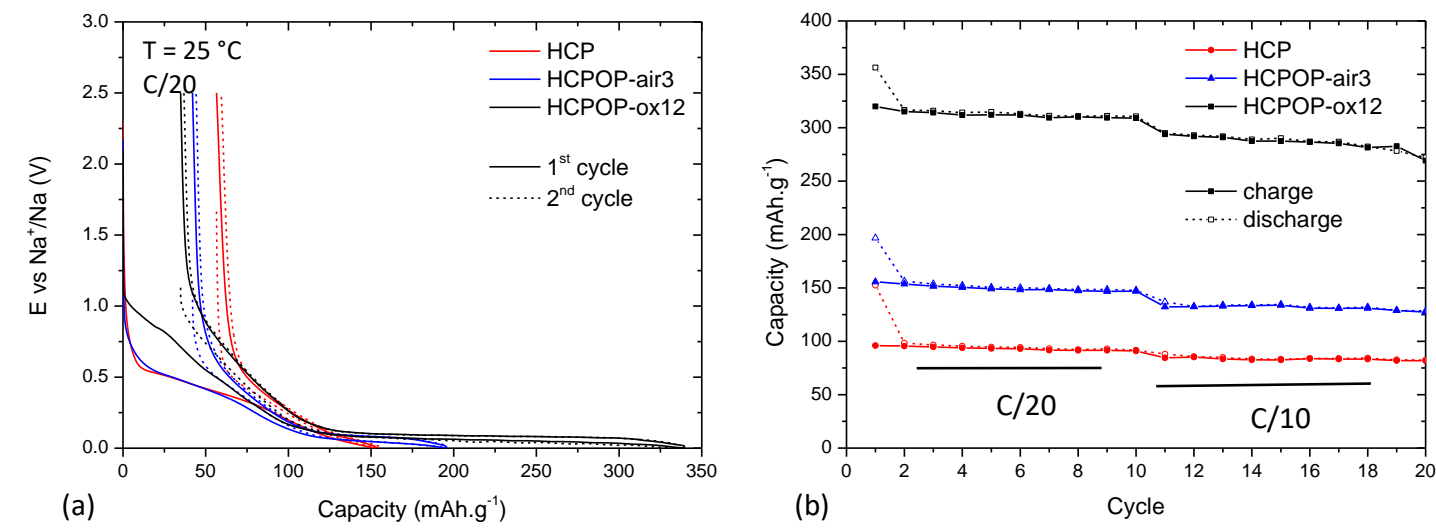

Figure 5. Electrochemical performances of HCP, HCPOP-air3 and HCPOP-ox12. (a) First galvanostatic curves at $\mathrm{C} / 20$ and (b) cyclability over 20 cycles.

The first galvanostatic curve for HCP shows almost no plateau region resulting in a very poor reversible capacity at first cycle of $96 \pm 0.005 \mathrm{mAh} . \mathrm{g}^{-1}$ (error given by the reproducibility on two coin-cells) for a current rate of $\mathrm{C} / 20$, as reported in

Table 4. This is due to its highly ordered structure as described above, which is not prone to host sodium. Performances of HCPOP-air3 shows a first interesting improvement as a plateau is slightly coming out delivering $154 \pm 1.2 \mathrm{mAh} \cdot \mathrm{g}^{-1}$ of total reversible capacity at first cycle with $69 \pm 0.07 \mathrm{mAh} . \mathrm{g}^{-1}$ attributed to the plateau region. However, these performances are still very far from the expectations. The best improvement once again is obtained with HCPOP-ox12 with a remarkable reversible capacity of $312 \pm 7.6 \mathrm{mAh} \cdot \mathrm{g}^{-1}$. The plateau region represents a very important contribution to the capacity with $190 \pm 4.3 \mathrm{mAh} \cdot \mathrm{g}^{-1}$, or in other words, more than $60 \%$ of the total reversible capacity. Moreover, irreversibility at first cycle is only of $10 \%$ when HCP had $37 \%$ and HCPOP-air3 21\%. As discussed previously, the strong decrease of irreversible capacity for HCPOP-ox12 is probably related to the reduction of the dangling bonds number by reaction with oxygen during the pitch pre-oxidation treatment, while maintaining a low specific 
surface area $\left(6.6 \mathrm{~m}^{2} \cdot \mathrm{g}^{-1}\right)$. The tuned hard carbon structure, brought by the control of the pretreatment conditions, allowed a strong improvement of the electrochemical performances of the hard carbon.

The oxygen pre-oxidized pitch-derived hard carbon shows remarkable performances which makes it the best sample to date for a pitch-derived hard carbon. Figure $\mathbf{5 b}$ reveals its good cycling performance with still a capacity of $252 \pm 17 \mathrm{mAh} . \mathrm{g}^{-1}$ after 20 cycles. Longer cycling stability and power rate capability were not possible to test in half-cells. Indeed, multiple studies showed that the use of metallic sodium as reference electrode is not reliable especially for long term cycling tests (mainly due to the low chemical stability of its SEI) and that extra care should be taken when concluding on two-electrode configuration half-cells results. ${ }^{65-70}$ That is why the behaviors herein presented are not aimed to be extrapolated to full cells conclusions. This may also explain the larger error on the capacity after 20 cycles. Assembly of full cells are underway to investigate high rate and long cycling performances.

Table 4. Electrochemical performances of the hard carbons at first cycle at C/20.

\begin{tabular}{|c|c|c|c|}
\hline Sample & ICE (\%) & $\begin{array}{l}\text { Reversible capacity } \\
\left(\mathrm{mAh} . \mathrm{g}^{-1}\right)\end{array}$ & Plateau (mAh.g $\left.{ }^{-1}\right)$ \\
\hline $\mathrm{HCP}$ & 63 & $96 \pm 0.005$ & $26 \pm 0.1$ \\
\hline HCPOP-air3 & $79 \pm 0.3$ & $154 \pm 1.2$ & $69 \pm 0.07$ \\
\hline HCPOP-ox12 & $90 \pm 0.02$ & $312 \pm 7.6$ & $190 \pm 4.3$ \\
\hline HCPOP-air12 & $86 \pm 0.1$ & $250 \pm 1.9$ & $136 \pm 0.3$ \\
\hline HCPOP-air48 & $84 \pm 0.4$ & $270 \pm 1.7$ & $152 \pm 0.3$ \\
\hline HCPOP-air72 & $87 \pm 0.005$ & $279 \pm 1.9$ & $162 \pm 0.2$ \\
\hline HCPOP-air200 & $78 \pm 0.3$ & $262 \pm 2.5$ & $148 \pm 2.5$ \\
\hline
\end{tabular}


Samples pre-oxidized under air flow were also tested as negative electrodes of SIBs and the first galvanostatic curves are shown in Figure S6 (Supporting Information). The results are consistent with the observations made above. The amorphization increases with the pre-oxidation time but also seems to reach a limit, which is confirmed with the reversible capacity at first cycle. It increases until $279 \pm 1.9 \mathrm{mAh}^{-1} \mathrm{~g}^{-1}$ for a 72 hours pre-oxidation step but then decreases to $262 \pm 2.5 \mathrm{mAh} . \mathrm{g}^{-1}$ for a 200 hours pre-oxidation treatment. Impressive performances reached with 12-hour-oxygen pre-oxidation treatment are not achieved here even though the optimization is clearly recorded.

The contributions of the slope and the plateau in the first reversible capacity are represented in Figure 6. It shows first the impressive improvement made from the pristine-pitchderived hard carbon HCP. Interestingly, the slope capacity presents very low evolution and stays around $115 \pm 1.9 \mathrm{mAh} . \mathrm{g}^{-1}$ for all the air pre-oxidized samples and $123 \pm 3.3 \mathrm{mAh} . \mathrm{g}^{-1}$ for the oxygen pre-oxidized one. It really is the plateau reversible capacity that changes a lot and brings most of the contribution to the overall capacity. Indeed, the longer the plateau, the higher the overall reversible capacity and the coulombic efficiency. This emphasizes once again the need to focus all studies on the plateau region that we believe is the key of improvement.

The irreversibility values are reported in

Table 3. When correlated to the BET specific surface areas, all the pretreated samples follow the same trend as the irreversibility increases when the surface area increases. Only HCP and HCPOP-air3 with their very small $\mathrm{S}_{\mathrm{BET}}$ do not follow the trend because their structures are the farthest from amorphous-like hard carbon. This highlights one more time the HCPOP-ox 12 
sample with the smallest $\mathrm{S}_{\mathrm{BET}}$ and the lowest irreversibility at first cycle. The best performances from a pre-oxidized pitch under air flow is obtained for a 72-hour pretreatment with $\mathrm{S}_{\mathrm{BET}}$ of 7.2 $\mathrm{m}^{2} \cdot \mathrm{g}^{-1}$ and an irreversibility at the first cycle of $13 \% \pm 0.005 \%$.

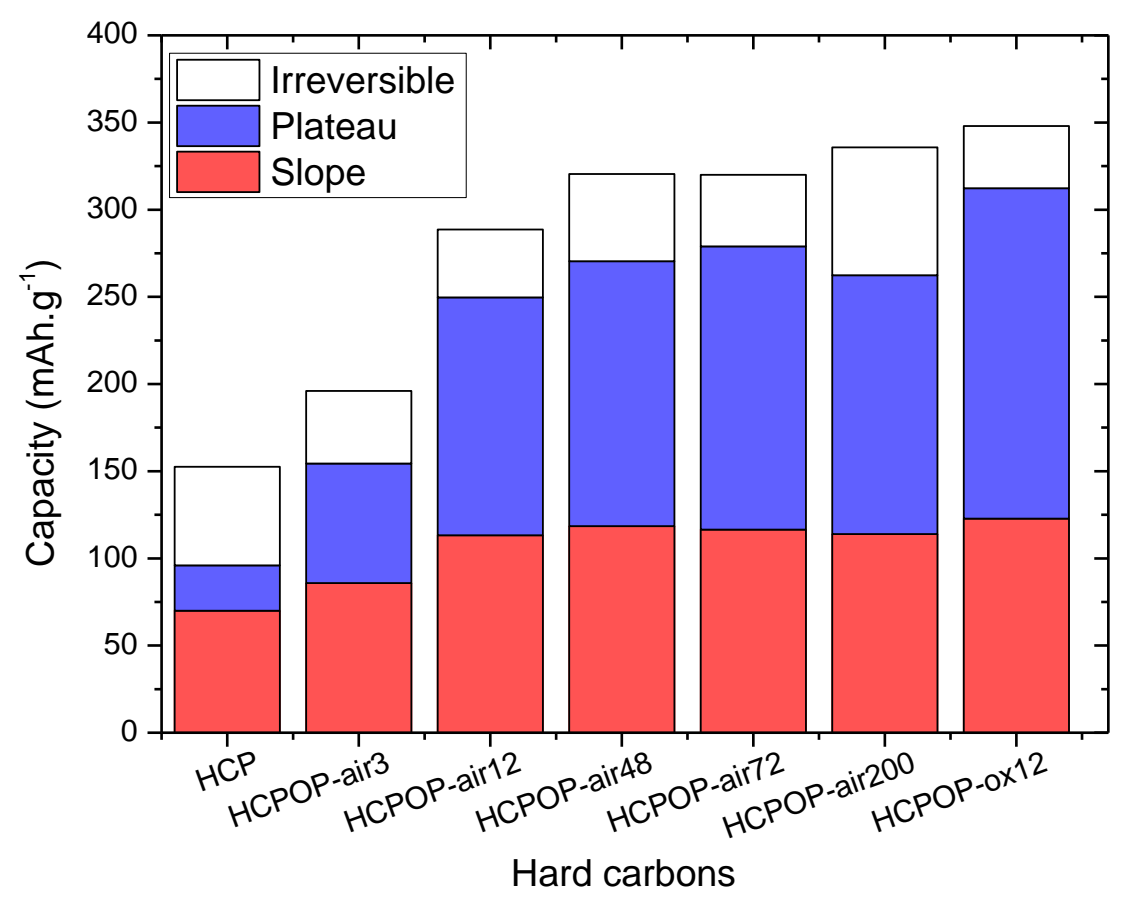

Figure 6. Irreversible capacity at the first cycle and contribution of the slope and the plateau in the first reversible capacity for all the HCs synthesized.

\section{CONCLUSIONS}

In this work, we have shown that improvements can easily be done to hinder pitch graphitization upon pyrolysis by a pre-oxidation treatment. Changing the pretreatment atmosphere was a key parameter and using oxygen flow ensured that more oxygen atoms are incorporated into the material to reticulate the structure. After pyrolysis, the resulting hard carbon with high yield of $49 \%$ gave impressive Na storage performances with a reversible 
capacity reaching $312 \mathrm{mAh} \cdot \mathrm{g}^{-1}$ at first cycle (C/20) and $90 \%$ of initial coulombic efficiency. These performances are the best obtained so far for a pitch-based hard carbon. The length of the plateau region (below $0.1 \mathrm{~V} v s . \mathrm{Na}^{+} / \mathrm{Na}$ ) was a key parameter of this remarkable improvement and contributes to $60 \%$ of the reversible capacity. Although pitch is a non-expensive material, has one of the highest carbon yield among usual hard carbon precursors and the process is easy to industrialize, the pre-oxidation atmosphere still needs to be changed (pure oxygen replaced by air) for safety and economic issues. The time of air pre-oxidation revealed to be an important parameter as the functionalization of the structure increased with increasing time. However, a limit in the electrochemical performances was reached and one should not exceed $72 \mathrm{~h}$ of pretreatment under these conditions. The high capacity obtained with oxygen pre-oxidation has not been reached so far with air pre-oxidation but working on pre-oxidation temperature could offer room for improvements. This study shows clearly the great influence of the pre-oxidation conditions on the hard carbon characteristics and the extra-care one need to take in order to improve its electrochemical performances.

\section{ASSOCIATED CONTENT}

Supporting Information. The following files are available free of charge.

XRD diagrams. TGA curve of pristine pitch. Deconvoluted C 1s spectra and area percentages of bond contributions obtained from these spectra. All data related to the air pre-oxidized pitch derived hard carbons: XRD diagrams, carbon characteristics calculated from XRD and Raman analyses, nitrogen adsorption isotherms and electrochemical performances. (PDF)

\section{AUTHOR INFORMATION}




\section{Corresponding Author}

*E-mail: raphael.janot@u-picardie.fr

\section{Funding Sources}

This work was funded by MERSEN France Gennevilliers through a CIFRE PhD project funding.

\section{Notes}

The authors declare no competing financial interest.

\section{ACKNOWLEDGMENT}

The authors thank very warmly Pardis SIMON for XPS measurements in UCCS Lille (France), and Sandrine ADACH for elemental analyses in L2CM Nancy (France). Matthieu COURTY (LRCS, Amiens) is also acknowledged for the TGA analysis.

\section{REFERENCES}

(1) Chu, S.; Majumdar, A. Opportunities and Challenges for a Sustainable Energy Future. Nature 2012, 488, 294-303. https://doi.org/10.1038/nature11475.

(2) Zhang, C.; Wei, Y.; Cao, P.; Lin, M. Energy Storage System : Current Studies on Batteries and Power Condition System. Renew. Sustain. Energy Rev. 2018, 82 (October 2017), 30913106. https://doi.org/10.1016/j.rser.2017.10.030.

(3) Divya, K. C.; Østergaard, J. Battery Energy Storage Technology for Power Systems - An Overview. Electr. Power Syst. Res. 2009, 79, 511-520. https://doi.org/10.1016/j.epsr.2008.09.017.

(4) Armand, M.; Tarascon, J. Building Better Batteries. Nature 2008, 451 (February), 652-657.

(5) Pan, H.; Hu, Y.; Chen, L. Room-Temperature Stationary Sodium-Ion Batteries for Large- 
Scale Electric Energy Storage. Energy Environ. Sci. 2013, 6 (8), 2338-2360. https://doi.org/10.1039/c3ee40847g.

(6) $\mathrm{Zu}, \mathrm{C}$;; Li, H. Thermodynamic Analysis on Energy Densities of Batteries. Energy Environ. Sci. 2011, 4, 2614-2624. https://doi.org/10.1039/c0ee00777c.

(7) Slater, M. D.; Kim, D.; Lee, E.; Johnson, C. S. Sodium-Ion Batteries. Adv. Funct. Mater. 2013, 23, 947-958. https://doi.org/10.1002/adfm.201200691.

(8) Górka, J.; Vix-Guterl, C.; Matei Ghimbeu, C. Recent Progress in Design of BiomassDerived Hard Carbons for Sodium Ion Batteries. C 2016, 2 (4), 24. https://doi.org/10.3390/c2040024.

(9) Kim, Y.; Ha, K.; Oh, S. M.; Tae, K. High-Capacity Anode Materials for Sodium-Ion Batteries. Chem. Eur. J. 2014, 20, 11980-11992. https://doi.org/10.1002/chem.201402511.

(10) Hwang, J.-Y.; Myung, S.-T.; Sun, Y.-K. Sodium-Ion Batteries: Present and Future. Chem. Soc. Rev. 2017, 46 (12), 3529-3614. https://doi.org/10.1039/C6CS00776G.

(11) Liu, Y.; Merinov, B. V; Goddard, W. A. Origin of Low Sodium Capacity in Graphite and Generally Weak Substrate Binding of $\mathrm{Na}$ and Mg among Alkali and Alkaline Earth Metals. Appl. Phys. Sci. 2016, 113 (14), 3735-3739. https://doi.org/10.1073/pnas.1602473113.

(12) Xiao, L.; Cao, Y.; Xiao, J.; Wang, W.; Kovarik, L.; Nie, Z.; Liu, J. High Capacity, Reversible Alloying Reactions in $\mathrm{SnSb} / \mathrm{C}$ Nanocomposites for Na-Ion Battery Applications. Chem. Commun. 2012, 48, 3321-3323. https://doi.org/10.1039/c2cc17129e.

(13) Qian, J.; Chen, Y.; Wu, L.; Cao, Y.; Ai, X.; Yang, H. High Capacity Na-Storage and Superior Cyclability of Nanocomposite Sb/C Anode for Na-Ion Batteries. Chem. Commun. 2012, 48, 7070-7072. https://doi.org/10.1039/c2cc32730a.

(14) Xu, Y.; Zhu, Y.; Liu, Y.; Wang, C. Electrochemical Performance of Porous Carbon/Tin 
Composite Anodes for Sodium-Ion and Lithium-Ion Batteries. Adv. Energy Mater. 2013, 3, 128-133. https://doi.org/10.1002/aenm.201200346.

(15) Pan, H.; Lu, X.; Yu, X.; Hu, Y.; Li, H.; Yang, X.; Chen, L. Sodium Storage and Transport Properties in Layered $\mathrm{Na}_{2} \mathrm{Ti}_{3} \mathrm{O}_{7}$ for Room-Temperature Sodium-Ion Batteries. Adv. Energy Mater. 2013, 3, 1186-1194. https://doi.org/10.1002/aenm.201300139.

(16) Ge, Y.; Jiang, H.; Zhu, J.; Lu, Y.; Chen, C.; Hu, Y.; Qiu, Y.; Zhang, X. High Cyclability of Carbon-Coated $\mathrm{TiO}_{2}$ Nanoparticles as Anode for Sodium-Ion Batteries. Electrochim. Acta 2015, 157, 142-148. https://doi.org/10.1016/j.electacta.2015.01.086.

(17) Hariharan, S.; Saravanan, K.; Balaya, P. $\alpha-\mathrm{MoO}_{3}$ : A High Performance Anode Material for Sodium-Ion Batteries. Electrochem. commun. 2013, 31, 5-9. https://doi.org/10.1016/j.elecom.2013.02.020.

(18) Su, D.; Ahn, H.; Wang, G. $\mathrm{SnO}_{2} @$ graphene Nanocomposites as Anode Materials for NaIon Batteries with Superior Electrochemical Performance. Chem. Commun. 2013, 49, 31313133. https://doi.org/10.1039/c3cc40448j.

(19) Sun, Q.; Ren, Q.; Li, H.; Fu, Z. High Capacity $\mathrm{Sb}_{2} \mathrm{O}_{4}$ Thin Film Electrodes for Rechargeable Sodium Battery. Electrochem. commun. 2011, 13 (12), 1462-1464. https://doi.org/10.1016/j.elecom.2011.09.020.

(20) Zhao, L.; Zhao, J.; Li, Y. H. H.; Zhou, Z.; Armand, M.; Chen, L. Disodium Terephthalate $\left(\mathrm{Na}_{2} \mathrm{C}_{8} \mathrm{H}_{4} \mathrm{O}_{4}\right)$ as High Performance Anode Material for Low-Cost Room-Temperature Sodium-Ion Battery. Adv. Energy Mater. 2012, 2, 962-965. https://doi.org/10.1002/aenm.201200166.

(21) Park, Y.; Shin, D.; Woo, S. H.; Choi, N. S.; Shin, K. H.; Oh, S. M.; Lee, K. T.; Hong, S. Y. Sodium Terephthalate as an Organic Anode Material for Sodium Ion Batteries. Adv. Mater. 
2012, 24, 3562-3567. https://doi.org/10.1002/adma.201201205.

(22) Zhao, Q.; Lu, Y.; Chen, J. Advanced Organic Electrode Materials for Rechargeable Sodium-Ion Batteries. Adv. Energy Mater. 2017, 7, 1601792. https://doi.org/10.1002/aenm.201601792.

(23) Ha, H.; Nam, S.; Jeong, S.; Hyun, S. Development of Covalent-Bonded Organic/Carbon Anode for Sodium-Ion Battery. J. Mech. Sci. Technol. 2019, 33 (8), 3865-3870. https://doi.org/10.1007/s12206-019-0730-2.

(24) Thomas, P.; Billaud, D. Electrochemical Insertion of Sodium into Hard Carbons. Electrochim. Acta 2002, 47 (20), 3303-3307. https://doi.org/10.1016/S0013$4686(02) 00250-5$.

(25) Komaba, S.; Murata, W.; Ishikawa, T.; Yabuuchi, N.; Ozeki, T.; Nakayama, T.; Ogata, A.; Gotoh, K.; Fujiwara, K. Electrochemical Na Insertion and Solid Electrolyte Interphase for Hard-Carbon Electrodes and Application to Na-Ion Batteries. Adv. Funct. Mater. 2011, 21 (20), 3859-3867. https://doi.org/10.1002/adfm.201100854.

(26) Bommier, C.; Surta, T. W.; Dolgos, M.; Ji, X. New Mechanistic Insights on Na-Ion Storage in Nongraphitizable Carbon. Nano Lett. 2015, 15 (9), 5888-5892. https://doi.org/10.1021/acs.nanolett.5b01969.

(27) Qiu, S.; Xiao, L.; Sushko, M. L.; Han, K. S.; Shao, Y.; Yan, M.; Liang, X.; Mai, L.; Feng, J.; Cao, Y.; Ai, X.; Yang, H.; Liu, J. Manipulating Adsorption-Insertion Mechanisms in Nanostructured Carbon Materials for High-Efficiency Sodium Ion Storage. Adv. Energy Mater. 2017, 7 (17), 1700403. https://doi.org/10.1002/aenm.201700403.

(28) Bommier, C.; Luo, W.; Gao, W. Y.; Greaney, A.; Ma, S.; Ji, X. Predicting Capacity of Hard Carbon Anodes in Sodium-Ion Batteries Using Porosity Measurements. Carbon N. Y. 2014, 
76, 165-174. https://doi.org/10.1016/j.carbon.2014.04.064.

(29) Li, X.; Liang, J.; Hou, Z.; Zhu, Y.; Qian, Y. Recycling Chicken Eggshell Membranes for High- Capacity Sodium Battery Anodes. RSC Adv. 2014, 4, 50950-50954. https://doi.org/10.1039/c4ra07995g.

(30) Hong, K.; Qie, L.; Zeng, R.; Yi, Z.; Zhang, W.; Wang, D.; Yin, W.; Wu, C.; Fan, Q.; Zhang, W.; Huang, Y. Biomass Derived Hard Carbon Used as a High Performance Anode Material for Sodium Ion Batteries. J. Mater. Chem. A 2014, 2, 12733-12738. https://doi.org/10.1039/c4ta02068e.

(31) Li, Y.; Xu, S.; Wu, X.; Yu, J.; Wang, Y.; Hu, Y.-S.; Li, H.; Chen, L.; Huang, X. Amorphous Monodispersed Hard Carbon Micro-Spherules Derived from Biomass as a High Performance Negative Electrode Material for Sodium-Ion Batteries. J. Mater. Chem. A 2015, 3 (1), 71-77. https://doi.org/10.1039/C4TA05451B.

(32) Luo, W.; Bommier, C.; Jian, Z.; Li, X.; Carter, R.; Vail, S.; Lu, Y.; Lee, J. J.; Ji, X. LowSurface-Area Hard Carbon Anode for Na-Ion Batteries via Graphene Oxide as a Dehydration Agent. ACS Appl. Mater. Interfaces 2015, 7 (4), 2626-2631. https://doi.org/10.1021/am507679x.

(33) Ponrouch, A.; Goñi, A. R.; Palacín, M. R. High Capacity Hard Carbon Anodes for Sodium Ion Batteries in Additive Free Electrolyte. Electrochem. commun. 2013, 27, 85-88. https://doi.org/10.1016/j.elecom.2012.10.038.

(34) Simone, V.; Boulineau, A.; de Geyer, A.; Rouchon, D.; Simonin, L.; Martinet, S. Hard Carbon Derived from Cellulose as Anode for Sodium Ion Batteries: Dependence of Electrochemical Properties on Structure. J. Energy Chem. 2016, 25 (5), 761-768. https://doi.org/10.1016/j.jechem.2016.04.016. 
(35) Zhu, H.; Shen, F.; Luo, W.; Zhu, S.; Zhao, M.; Natarajan, B.; Dai, J.; Zhou, L.; Ji, X.; Yassar, R. S.; Li, T.; Hu, L. Low Temperature Carbonization of Cellulose Nanocrystals for High Performance Carbon Anode of Sodium-Ion Batteries. Nano Energy 2017, 33 (January), 37-44. https://doi.org/10.1016/j.nanoen.2017.01.021.

(36) Luo, W.; Schardt, J.; Bommier, C.; Wang, B.; Razink, J.; Simonsen, J.; Ji, X. Carbon Nanofibers Derived from Cellulose Nanofibers as a Long-Life Anode Material for Rechargeable Sodium-Ion Batteries. J. Mater. Chem. A 2013, 1 (36), 10662. https://doi.org/10.1039/c3ta12389h.

(37) Alcántara, R.; Lavela, P.; Ortiz, G. F.; Tirado, J. L. Carbon Microspheres Obtained from Resorcinol-Formaldehyde as High-Capacity Electrodes for Sodium-Ion Batteries. Electrochem. Solid-State Lett. 2005, 8 (4), A222. https://doi.org/10.1149/1.1870612.

(38) Hasegawa, G.; Kanamori, K.; Kannari, N.; Ozaki, J. Hard Carbon Anodes for Na-Ion Batteries: Toward a Practical Use. ChemElectroChem 2015, 2, 1917-1920. https://doi.org/10.1002/celc.201500412.

(39) Hasegawa, G.; Kanamori, K.; Kannari, N.; Ozaki, J.; Nakanishi, K.; Abe, T. Studies on Electrochemical Sodium Storage into Hard Carbons with Binder-Free Monolithic Electrodes. $\quad$ J. $\quad$ Power $\quad$ Sources $\quad$ 2016, $318, \quad 48$. https://doi.org/10.1016/j.jpowsour.2016.04.013.

(40) Wang, H.; Shi, Z.; Jin, J.; Chong, C.; Wang, C. Properties and Sodium Insertion Behavior of Phenolic Resin-Based Hard Carbon Microspheres Obtained by a Hydrothermal Method. J. Electroanatlytical Chem. $\quad$ 2015, 87-91. https://doi.org/10.1016/j.jelechem.2015.07.032.

(41) Beda, A.; Taberna, P.; Simon, P. Hard Carbons Derived from Green Phenolic Resins for 
Na-Ion Batteries. Carbon N. $\quad$ Y. $\quad$ 2018, $139, \quad 248-257$. https://doi.org/10.1016/j.carbon.2018.06.036.

(42) Mayes, R. T.; Tsouris, C.; Jr, O. K.; Mahurin, S. M.; Depaoli, W. Hierarchical Ordered Mesoporous Carbon from Phloroglucinol-Glyoxal and Its Application in Capacitive Deionization of Brackish Water. J. Mater. Chem. 2010, 20, 8674-8678. https://doi.org/10.1039/c0jm01911a.

(43) Jin, J.; Yu, B. J.; Shi, Z. Q.; Wang, C. Y.; Chong, C. Bin. Lignin-Based Electrospun Carbon Nanofibrous Webs as Free-Standing and Binder-Free Electrodes for Sodium Ion Batteries. J. Power Sources 2014, 272, 800-807. https://doi.org/10.1016/j.jpowsour.2014.08.119.

(44) Chang, Z.-Z.; Yu, B. J.; Wang, C.-Y. Influence of H2 Reduction on Lignin-Based Hard Carbon Performance in Lithium Ion Batteries. Electrochim. Acta 2015, 176, 1352-1357. https://doi.org/10.1016/j.electacta.2015.07.076.

(45) Liu, P.; Li, Y.; Hu, Y.; Li, H.; Chen, L.; Huang, X. A Waste Biomass Derived Hard Carbon as a High-Performance Anode Material for Sodium-Ion Batteries. J. Mater. Chem. A. 2016, 4, 13046-13052. https://doi.org/10.1039/C6TA04877C.

(46) Xiang, J.; Lv, W.; Mu, C.; Zhao, J.; Wang, B. Activated Hard Carbon from Orange Peel for Lithium/Sodium Ion Battery Anode with Long Cycle Life. J. Alloys Compd. 2017, 701, 870-874. https://doi.org/10.1016/j.jallcom.2017.01.206.

(47) Li, W.; Huang, J.; Feng, L.; Cao, L.; Ren, Y.; Li, R.; Xu, Z.; Li, J.; Yao, C. Controlled Synthesis of Macroscopic Three-Dimensional Hollow Reticulate Hard Carbon as Long-Life Anode Materials for Na-Ion Batteries. J. Alloys Compd. 2017, 716, 210-219. https://doi.org/10.1016/j.jallcom.2017.05.062.

(48) Wang, K.; Jin, Y.; Sun, S.; Huang, Y.; Peng, J.; Luo, J.; Zhang, Q.; Qiu, Y.; Fang, C.; Han, 
J. Low-Cost and High-Performance Hard Carbon Anode Materials for Sodium-Ion Batteries. ACS Omega 2017, 2, 1687-1695. https://doi.org/10.1021/acsomega.7b00259.

(49) Zhu, Y.; Chen, M.; Li, Q.; Yuan, C.; Wang, C. A Porous Biomass-Derived Anode for HighPerformance Sodium-Ion Batteries. Carbon N. Y. 2018, 129, 695-701. https://doi.org/10.1016/j.carbon.2017.12.103.

(50) Wenzel, S.; Hara, T.; Janek, J.; Adelhelm, P. Room-Temperature Sodium-Ion Batteries : Improving the Rate Capability of Carbon Anode Materials by Templating Strategies. Energy Environ. Sci. 2011, 4, 3342-3345. https://doi.org/10.1039/c1ee01744f.

(51) Li, Y.; Mu, L.; Hu, Y. S.; Li, H.; Chen, L.; Huang, X. Pitch-Derived Amorphous Carbon as High Performance Anode for Sodium-Ion Batteries. Energy Storage Mater. 2016, 2, 139145. https://doi.org/10.1016/j.ensm.2015.10.003.

(52) Li, Y.; Hu, Y.-S.; Li, H.; Chen, L.; Huang, X. A Superior Low-Cost Amorphous Carbon Anode Made from Pitch and Lignin for Sodium-Ion Batteries. J. Mater. Chem. A 2016, 4 (1), 96-104. https://doi.org/10.1039/C5TA08601A.

(53) Yang, S.; Dong, W.; Shen, D.; Li, S.; Sun, W.; Hong, X.; Wang, M.; Mao, Y. Composite of Nonexpansion Reduced Graphite Oxide and Carbon Derived from Pitch as Anodes of NaIon Batteries with High Coulombic Efficiency. Chem. Eng. J. 2017, 309, 674-681. https://doi.org/10.1016/j.cej.2016.10.074.

(54) Lu, Y.; Zhao, C.; Qi, X.; Qi, Y.; Li, H.; Huang, X.; Chen, L.; Hu, Y. S. Pre-OxidationTuned Microstructures of Carbon Anodes Derived from Pitch for Enhancing Na Storage Performance. Adv. Energy Mater. 2018, $8 \quad$ (27), 1-6. https://doi.org/10.1002/aenm.201800108.

(55) Mallet, P. Analyse Multiéchelle de Carbones Pyrolytiques, Université de Toulouse, 2014. 
(56) Cuesta, A.; Dhamelincourt, P.; Laureyns, J.; Martínez-Alonso, A.; Tascón, J. M. D. Raman Microprobe Studies on Carbon Materials. Carbon N. Y. 1994, 32 (8), 1523-1532. https://doi.org/10.1016/0008-6223(94)90148-1.

(57) Jawhari, T.; Roid, A.; Casado, J. Raman Spectroscopic Characterization of Some Commercially Available Carbon Black Materials. Carbon N. Y. 1995, 33 (11), 1561-1565. https://doi.org/10.1016/0008-6223(95)00117-V.

(58) Ammar, M. R.; Rouzaud, J. N. How to Obtain a Reliable Structural Characterization of Polished Graphitized Carbons by Raman Microspectroscopy. J. Raman Spectrosc. 2012, 43 (2), 207-211. https://doi.org/10.1002/jrs.3014.

(59) Sadezky, A.; Muckenhuber, H.; Grothe, H.; Niessner, R.; Pöschl, U. Raman Microspectroscopy of Soot and Related Carbonaceous Materials: Spectral Analysis and Structural Information. Carbon N. $\quad Y . \quad \mathbf{2 0 0 5}, 43 \quad(8), \quad$ 1731-1742. https://doi.org/10.1016/j.carbon.2005.02.018.

(60) Mallet-Ladeira, P.; Puech, P.; Toulouse, C.; Cazayous, M.; Ratel-Ramond, N.; Weisbecker, P.; Vignoles, G. L.; Monthioux, M. A Raman Study to Obtain Crystallite Size of Carbon Materials: A Better Alternative to the Tuinstra-Koenig Law. Carbon N. Y. 2014, 80 (1), 629-639. https://doi.org/10.1016/j.carbon.2014.09.006.

(61) Jurkiewicz, K.; Duber, S.; Fischer, H. E.; Burian, A. Modelling of Glass-like Carbon Structure and Its Experimental Verification by Neutron and X-Ray Diffraction. J. Appl. Crystallogr. 2017, 50 (1), 36-48. https://doi.org/10.1107/S1600576716017660.

(62) Jurkiewicz, K.; Pawlyta, M.; Zygadło, D.; Chrobak, D.; Duber, S.; Wrzalik, R.; Ratuszna, A.; Burian, A. Evolution of Glassy Carbon under Heat Treatment: Correlation StructureMechanical Properties. J. Mater. Sci. 2018, 53 (5), 3509-3523. 
https://doi.org/10.1007/s10853-017-1753-7.

(63) Farokh Niaei, A. H.; Hussain, T.; Hankel, M.; Searles, D. J. Hydrogenated Defective Graphene as an Anode Material for Sodium and Calcium Ion Batteries: A Density Functional Theory Study. Carbon $N . \quad Y$. 2018, 136 (May), 73-84. https://doi.org/10.1016/j.carbon.2018.04.034.

(64) Kubota, K.; Shimadzu, S.; Yabuuchi, N.; Tominaka, S.; Shiraishi, S.; Abreu-Sepulveda, M.; Manivannan, A.; Gotoh, K.; Fukunishi, M.; Dahbi, M.; Komaba, S. Structural Analysis of Sucrose-Derived Hard Carbon and Correlation with the Electrochemical Properties for Lithium, Sodium, and Potassium Insertion. Chem. Mater. 2020, 32 (7), 2961-2977. https://doi.org/10.1021/acs.chemmater.9b05235.

(65) Bommier, C.; Leonard, D.; Jian, Z.; Stickle, W. F.; Greaney, P. A.; Ji, X. New Paradigms on the Nature of Solid Electrolyte Interphase Formation and Capacity Fading of Hard Carbon Anodes in Na-Ion Batteries. Adv. Mater. Interfaces 2016, 3 (19), 1600449. https://doi.org/10.1002/admi.201600449.

(66) Rupp, R.; Vlad, A. On the Reliability of Sodium Metal Anodes: The Influence of Neglected Parameters. J. Electrochem. Soc. 2019, 166 (14), A3122-A3131. https://doi.org/10.1149/2.0161914jes.

(67) Dugas, R.; Forero-Saboya, J. D.; Ponrouch, A. Methods and Protocols for Reliable Electrochemical Testing in Post-Li Batteries (Na, K, Mg, and Ca). Chem. Mater. 2019, No. Cv. https://doi.org/10.1021/acs.chemmater.9b02776.

(68) Tchitchekova, D. S.; Monti, D.; Johansson, P.; Bardé, F.; Randon-Vitanova, A.; Palacín, M. R.; Ponrouch, A. On the Reliability of Half-Cell Tests for Monovalent $\left(\mathrm{Li}^{+}, \mathrm{Na}^{+}\right)$and Divalent $\left(\mathrm{Mg}^{2+}, \mathrm{Ca}^{2+}\right)$ Cation Based Batteries . J. Electrochem. Soc. 2017, 164 (7), A1384- 
A1392. https://doi.org/10.1149/2.0411707jes.

(69) Iermakova, D. I.; Dugas, R.; Palacín, M. R.; Ponrouch, A. On the Comparative Stability of $\mathrm{Li}$ and $\mathrm{Na}$ Metal Anode Interfaces in Conventional Alkyl Carbonate Electrolytes. $J$. Electrochem. Soc. 2015, 162 (13), A7060-A7066. https://doi.org/10.1149/2.0091513jes.

(70) Li, Z.; Jian, Z.; Wang, X.; Rodríguez-Pérez, I. A.; Bommier, C.; Ji, X. Hard Carbon Anodes of Sodium-Ion Batteries: Undervalued Rate Capability. Chem. Commun. 2017, 53 (17), 2610-2613. https://doi.org/10.1039/C7CC00301C.

\section{TABLE OF CONTENTS GRAPHIC}

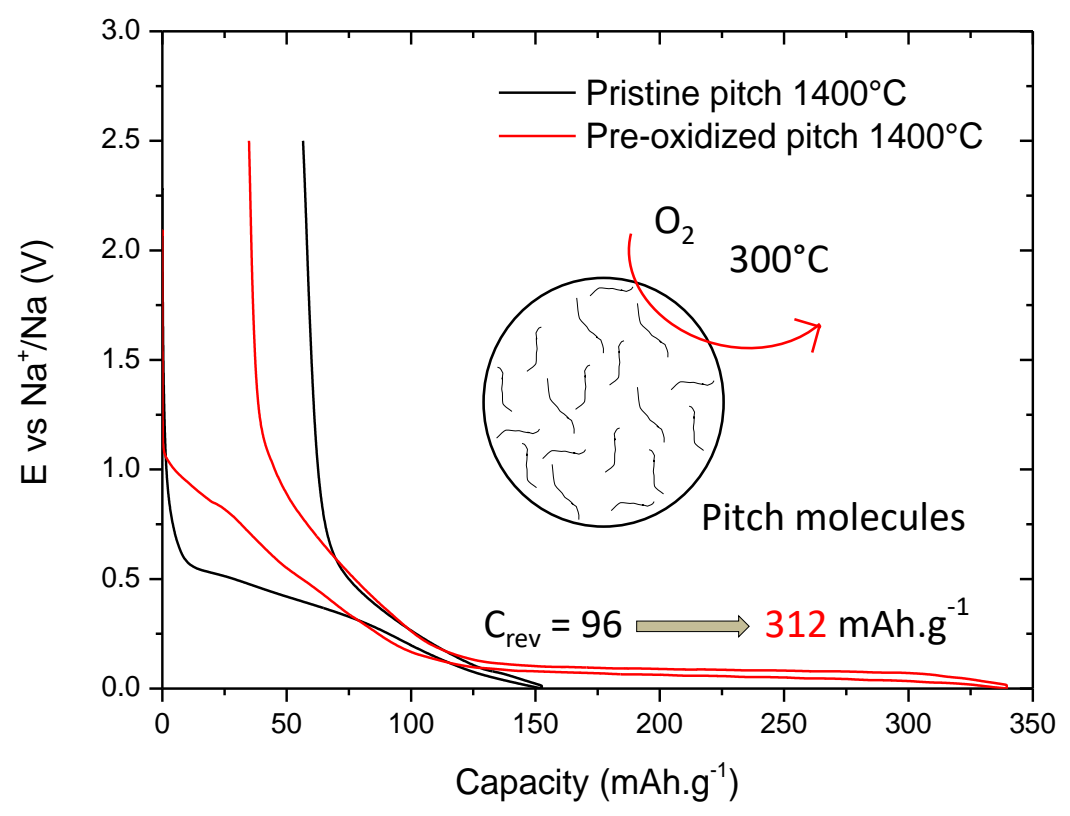

